\title{
Marital status and risk of cardiovascular diseases: a systematic review and meta-analysis
}

\author{
Chun Wai Wong, ${ }_{1}^{1}$ Chun Shing Kwok, ${ }_{1}^{1}$ Aditya Narain, ${ }^{1}$ Martha Gulati, ${ }^{2}$ \\ Anastasia S Mihalidou, ${ }^{3}$ Pensee Wu, ${ }^{4,5}$ Mirvat Alasnag, ${ }^{6}$ Phyo Kyaw Myint, ${ }^{7}$ \\ Mamas A Mamas ${ }^{1}$
}

- Additional material is published online only. To view please visit the journal online (http://dx.doi.org/10.1136/ heartjnl-2018-313005).

For numbered affiliations see end of article.

Correspondence to Dr Chun Shing Kwok, Cardiovascular Research Group, Keele University, Stoke-on-Trent ST4 7QB, UK; shingkwok@ doctors.org.uk

Received 14 January 2018 Revised 18 April 2018 Accepted 19 April 2018 Published Online First 19 June 2018

\section{Linked}

- http://dx.doi.org/10.1136/ heartjnl-2018-313469

- http://dx.doi.org/10.1136/ heartjnl-2018-313815

Check for updates

To cite: Wong CW, Kwok CS, Narain A, et al. Heart

2018:104:1937-1948.

\section{ABSTRACT}

Background The influence of marital status on the incidence of cardiovascular disease (CVD) and prognosis after CVD is inconclusive. We systematically reviewed the literature to determine how marital status influences CVD and prognosis after CVD.

Methods A search of MEDLINE and Embase in January 2018 without language restriction was performed to identify studies that evaluated the association between marital status and risk of CVD. Search terms related to both marital status and CVD were used and included studies had to be prospective in design. The outcomes of interest were CVD, coronary heart disease (CHD) or stroke incidence and mortality. We performed random effects meta-analysis stratified by the types of population by calculating odds ratios (OR) and 95\% confidence intervals $(95 \% \mathrm{Cl})$.

Results Our analysis included 34 studies with more than two million participants. Compared with married participants, being unmarried (never married, divorced or widowed) was associated with increased odds of CVD (OR 1.42; 95\% Cl 1.00 to 2.01), CHD (OR $1.16,95 \% \mathrm{Cl} 1.04$ to 1.28 ), CHD death (OR $1.43,95 \%$ $\mathrm{Cl} 1.28$ to 1.60 ) and stroke death (OR $1.55,95 \% 1.16$ to 2.08). Being divorced was associated with increased odds of CHD ( $P<0.001)$ for both men and women while widowers were more likely to develop a stroke $(P<0.001)$. Single men and women with myocardial infarction had increased mortality (OR 1.42, 95\% Cl 1.14 to 1.76) compared with married participants.

Conclusions Marital status appears to influence CVD and prognosis after CVD. These findings may suggest that marital status should be considered in the risk assessment for CVD and outcomes of CVD based on marital status merits further investigation.

\section{INTRODUCTION}

Cardiovascular disease (CVD) is associated with significant morbidity and mortality. ${ }^{1}$ In order to reduce the burden of CVD, there is great interest in identifying risk factors in the general population so that those deemed to be at high risk for future cardiovascular events can be targeted for intervention. While $80 \%$ of the risk for future CVD can be predicted from known cardiovascular risk factors such as old age, male sex, hypertension, hyperlipidaemia, smoking and diabetes mellitus, the determinants for the remaining 20\% risk remain unclear. ${ }^{2}$

One factor which may be associated with CVD is marital status and studies have reported inconsistent findings. The benefits of marriage on health and mortality have been demonstrated for both sexes, in different ethnic groups and appear to be independent of various sociodemographic characteristics. ${ }^{3}{ }^{4}$ Better prognosis in married individuals has been reported both after myocardial infarction ${ }^{3-10}$ and stroke, ${ }^{11} 12$ whereas, other studies found no influence of marital status on risk of future CVD. ${ }^{13-15}$ In addition, sex differences have been observed where the degree of 'protection' conferred in men from being married tends to be greater. ${ }^{16} 17$ The interpretation of marital status and CVD becomes more complex with the addition of divorced and widowed groups. ${ }^{15}$ 18-20

In view of these disparate findings reported in the literature, we conducted a systematic review and meta-analysis to evaluate the risk of CVD based on marital status and the influence of marital status on prognosis after CVD.

\section{METHODS}

This systematic review and meta-analysis was conducted and reported according to the guidance of the Preferred Reporting Items for Systematic Reviews and Meta-Analysis (PRISMA). ${ }^{21}$

\section{Eligibility criteria}

We selected studies which evaluated cardiovascular events or mortality in participants according to marital status. The included studies had at least two groups (married and unmarried, divorced or widowed) and followed participants for incident cardiovascular events or mortality outcome after incident CVD. Studies of patients with suspected coronary heart disease were also included but not pooled with other studies with myocardial infarction. Only prospective studies published since 2000 were retained for analysis to limit issues related to quality of study reporting and generalisability to contemporary clinical practice. There was no exclusion of studies based on the length of follow-up, language of publication or definition of cardiovascular events such as ischaemic heart disease, coronary heart disease, myocardial infarction and stroke. However, we excluded studies of heart failure, retrospective analyses, case-control studies and those studies which did not report the numerical association between marital status and outcome. Reviews were examined for additional studies that met the inclusion criteria. 


\section{Search strategy}

We searched MEDLINE and Embase from 2000 onwards using OVID SP with no date or language restriction. This search was last updated in January 2018. The exact free search terms were ('marital status' or 'married' or 'unmarried' or 'widowed' or 'divorced') AND ('myocardial infarction' or 'acute coronary syndrome' or 'coronary heart disease' or 'ischaemic heart disease' or 'ischaemic heart disease' or 'heart attack' or 'stroke' or 'cerebrovascular disease' or 'cerebrovascular accident'). We checked the bibliography of relevant studies and reviews for additional studies that met the inclusion criteria.

\section{Study selection process and data collection process}

Two reviewers (CWW and CSK) independently screened all titles and abstracts retrieved from the search for studies that met the inclusion criteria. The full articles of studies that potentially met the inclusion criteria were reviewed and the final decision to include or exclude was made with the other reviewers. Independent double extractions were performed by two reviewers (CWW and CSK) collecting data on study design, year, country, number of participants, mean age, \% male, participant inclusion criteria, comparison groups and results, while independent double extractions for quality assessment table were completed by CWW and another reviewer (AN).

\section{Risk of bias assessment}

Quality assessment of the studies was conducted based on the recommendations of the Cochrane Handbook for Systematic Review and previous published systematic reviews of observational studies. ${ }^{22}$

\section{Data analysis}

We used Review Manager V.5.3.5 (Nordic Cochrane Centre) to conduct random effects meta-analysis stratified by the type of population which were either general population, post stroke or post myocardial infarction and marital status. We used random effects because the studies were conducted in a wide range of settings in different populations, hence the need to take heterogeneity into account for the pooled effect estimate. Where possible, we chose to pool reported adjusted risk estimates from primary studies and when these data were not available, raw data were used to calculate unadjusted risk estimates. We used the $\mathrm{I}^{2}$ statistic to assess statistical heterogeneity. $\mathrm{I}^{2}$ values of $30-60 \%$ represent moderate levels of heterogeneity and sensitivity analysis was performed to evaluate analyses with high statistical heterogeneity. Publication bias was assessed by asymmetry testing with funnel plots if there was no evidence of significant heterogeneity. ${ }^{23}$ Further subgroup analyses were performed to investigate the impact of sex differences combined with marital status on various cardiovascular outcomes. Further analyses were also performed with the exclusion of studies with unclear marital status ascertainment and another with the exclusion of studies with only crude results or unadjusted results available.

\section{RESULTS}

\section{Description of studies included in analysis}

The process of study selection is shown in figure 1. After screening, 32 studies were retained for inclusion and two additional studies were identified from a review yielding a total of 34 studies for analysis. Table 1 summarises the study designs and participant characteristics. These 34 studies, which took place in various countries including Russia, Denmark, Spain, USA, Sweden, UK, Canada, Israel, Gulf States, Japan, Finland,

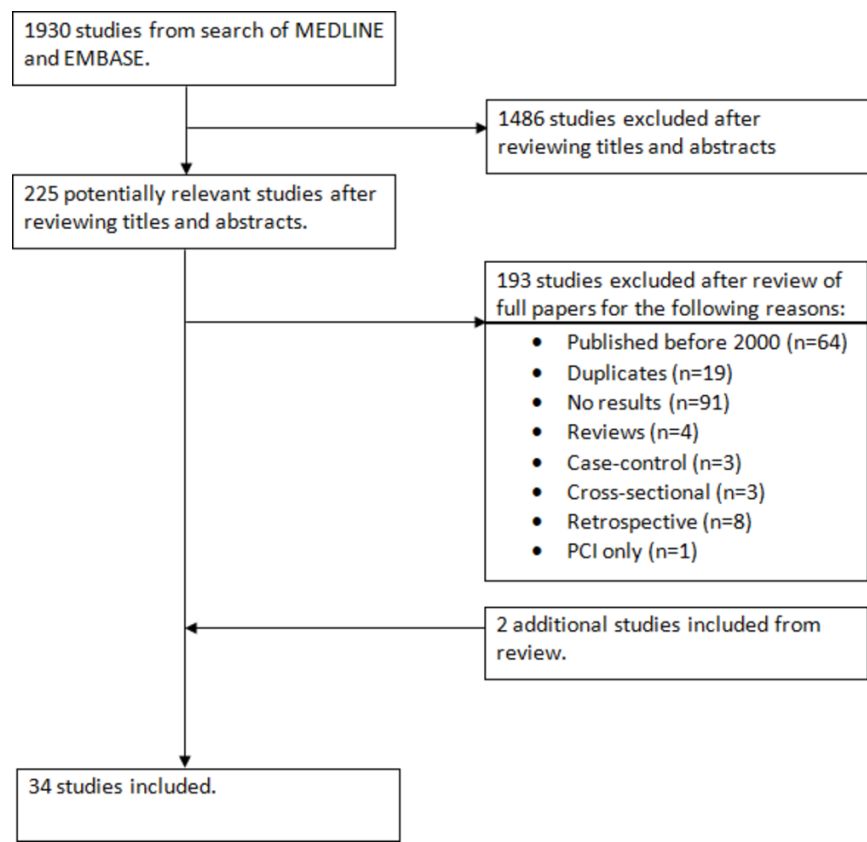

Figure 1 Flow diagram of study selection.

Greece, Turkey, Norway and China between 1963 and 2015. The follow-up period from these studies ranged from 30 days to 34 years. There were more than 2 million participants (ranging from 135 to 734626 participants). Data on age are available for 1137571 participants from 25 studies with a mean of 58.4 years (range 42 to 77 years). The definition of unmarried used in each study is presented in the online supplementary table 1 .

\section{Quality assessment of included studies}

The quality assessment of included studies is summarised in online supplementary table 2. Twenty-four studies were found to have used reliable methods for ascertaining the marital status which involved utilising databases, ${ }^{71114-16202425}$ questionnaires, ${ }^{2} 9131718$ 26-29 and interviews. ${ }^{912} 192530-34$ Reliable outcome ascertainment was found in 25 studies either from databases, ${ }^{671113-1820242528-30323335-37}$ medical records, ${ }^{67131617303134}$ or assessment by healthcare professionals or research teams. ${ }^{2181929}$ Seventeen studies reported a low rate of loss to follow-up of $<10 \%$. $^{267913-1517-20242930323335}$ Twenty-nine studies included adjusted analyses, ${ }^{36-10}$ 13-20 24-27 2931 33-38 three studies included unadjusted analysis ${ }^{9} 1112$ and five studies had only crude results available. ${ }^{2} 30323940$ For assessment of publication bias, the funnel plots conducted showed no significant asymmetry in the pattern of distribution of studies (online supplementary figures 1-14).

\section{Pooled analysis of marital status and cardiovascular outcomes}

Mortality in the general population

The results for the general population as well as by gender are summarised in tables 2-4 (and online supplementary table 2 and online supplementary figures 1-2 and 4-13). Compared with married participants, unmarried participants were more likely to die from both CHD (OR $1.43,95 \%$ CI 1.28 to $1.60, \mathrm{I}^{2}=57 \%$, $\mathrm{P}<0.001, \mathrm{n}=5$ ) and stroke (OR $1.55,95 \% \mathrm{CI} 1.16$ to 2.08 , $\mathrm{I}^{2}=0 \%, \mathrm{P}=0.003, \mathrm{n}=2$ ) (figure $2 \mathrm{~A}$ and figure $2 \mathrm{~B}$ ).

Being divorced was associated with an increased odds of $\mathrm{CHD}$ mortality (OR 1.33, 95\% CI 1.04 to $1.70, \mathrm{I}^{2}=0 \%, \mathrm{n}=3$ ) (online 
Table 1 Study design and participant characteristics

\begin{tabular}{|c|c|c|c|c|c|}
\hline Study ID & Study design; country; design & Total participants & Mean age & $\%$ male & Inclusion criteria \\
\hline Akimova $2014^{35}$ & Prospective cohort study; Russia; 1996-2008 & 1609 & - & 49.4 & Participants were Tyumen citizens aged $25-64$ years \\
\hline Andersen $2011^{11}$ & Prospective cohort study; Denmark; 2000-2007 & 26818 & 71.2 & 51.5 & $\begin{array}{l}\text { Participants were patients with first-ever ischaemic stroke admission aged } 18 \text { and above in the Danish } \\
\text { National Indicator Project }\end{array}$ \\
\hline Bell $2013^{26}$ & $\begin{array}{l}\text { Post-hoc analysis of trial and cohort study; USA; } \\
\text { 1993-2010 }\end{array}$ & 3173 & $\begin{array}{l}\text { Mean age at } \\
\text { stroke was } 72.6\end{array}$ & 0 & $\begin{array}{l}\text { Participants were post-menopausal women aged 50-79, who were stroke-free at baseline with incident } \\
\text { stroke before } 2005 \text { in the Women's Health Initiative trial }\end{array}$ \\
\hline Consuegra-Sanchez $2015^{6}$ & Prospective cohort study; Spain; 1998-2013 & 7408 & 66.1 & 73.3 & $\begin{array}{l}\text { Participants were patients with acute Ml aged } 18 \text { and above who were admitted to the coronary care units } \\
\text { of two hospitals in the Murcia region within } 24 \text { hours }\end{array}$ \\
\hline Dupre $2015^{19}$ & Prospective cohort study; USA; $1992-2010$ & 15827 & 54.3 & 45.9 & Participants were ever married adults aged $45-80$ years in the Health and Retirement Study \\
\hline Dupre $201^{30}$ & Prospective cohort study; USA; $1992-2010$ & 2197 & 69.5 & 55.1 & Participants had MI during the follow-up period in the Health and Retirement Study \\
\hline Eaker $2007^{27}$ & Prospective cohort study; USA; 1971-1987 & 3682 & 48.5 & 48.1 & $\begin{array}{l}\text { Participants were in the Framingham Offspring Study, consisting of the offspring (and their spouses) of the } \\
\text { Framingham Heart Study Original Cohort, enrolled in } 1971 \text { to } 1974\end{array}$ \\
\hline Engstrom $2000^{14}$ & Prospective cohort study; Sweden; 1977-1994 & 9351 & 48.5 & 0 & $\begin{array}{l}\text { Participants were women aged } 28-55 \text { years who attended the health examination programme at the } \\
\text { Department of Preventive Medicine in Malmo }\end{array}$ \\
\hline Engstrom $2004^{28}$ & Prospective cohort study; Sweden; $1990-2000$ & 118134 & 60 & 44.8 & Participants were individuals aged between 40-89years in Malmo, Sweden \\
\hline Engstrom $2006^{20}$ & Prospective cohort study; Sweden; 1974-1997 & 6075 & 46.8 & 100 & Participants were men without history of Ml, stroke or cancer aged 28-61 years in Malmo, Sweden \\
\hline Floud $2014^{13}$ & Prospective study; UK; 1996-2011 & 734626 & 59.7 & 0 & Participants were women without history of heart disease or stroke in the Million Women Study \\
\hline Gerward $2010^{7}$ & Prospective cohort study; Sweden; 1974-2004 & 3542 & - & 85.7 & Participants were individuals aged 27-61 years without history of MI in the Malmo Preventive Project \\
\hline Ghosh-Swaby $2016^{38}$ & $\begin{array}{l}\text { Prospective cohort study; Canada; published } \\
\text { in } 2016\end{array}$ & 2100 & - & - & Participants had PCl after MI in the Canadian Observational Antiplatelet Study \\
\hline Golbourt $2010^{36}$ & Prospective cohort study; Israel; 1963-1997 & 10059 & 49.2 & 100 & Participants were male civil servants and municipal employees in the Israeli Ischaemic Heart Disease study \\
\hline Hadi $2012^{8}$ & $\begin{array}{l}\text { Prospective cohort study; Gulf States; } \\
\text { 2008-2009 }\end{array}$ & 5334 & 56.8 & 79.0 & Participants were post-ACS patients in the second Gulf Registry of Acute Coronary Events \\
\hline Ikeda $2009^{17}$ & Prospective cohort study; Japan; 1990-2004 & 90987 & 51.9 & 47.7 & $\begin{array}{l}\text { Participants were Japan residents aged } 40-69 \text { years in the first and second cohort of the Japan Public } \\
\text { health Centre-based Prospective Study }\end{array}$ \\
\hline Janzon $2004^{24}$ & Prospective cohort study; Sweden; 1977-1998 & 10621 & 49.6 & 0 & Participants were women without history of Ml or stroke aged between 28-58 in Malmo, Sweden \\
\hline Jayaram $2013^{39}$ & Prospective cohort study; US; 2003-2008 & 4853 & 50 to 80 & 66.7 & Participants were post-acute MI patients aged 50 to 80 years from 31 USA sites. \\
\hline Kilpi $2015^{16}$ & Prospective cohort study; Finland; 1987-2007 & 299281 & - & 49.4 & Participants were individuals aged above 15 years in Finland \\
\hline Kriegbaum $2008^{15}$ & Prospective cohort study; Denmark; $1980-2005$ & 8865 & 28 to 39 & 100 & Participants were men born in Copenhagen in 1953 and living in Denmark in 1968 \\
\hline Malyutina $2004^{18}$ & Prospective cohort study; Russia; 1984-1998 & 11404 & 25 to 64 & 56.9 & Participants were residents in Novosibirsk aged 25-64 years in the WHO MONICA Project \\
\hline Maselko $2009^{31}$ & Prospective cohort study; USA; $1992-2006$ & 22818 & 63.9 & 56 & $\begin{array}{l}\text { Participants were individuals born between } 1900-1947 \text { aged } 50 \text { years or above without history of stroke in } \\
\text { the Health and Retirement Study }\end{array}$ \\
\hline Matthews $2002^{29}$ & $\begin{array}{l}\text { Post-hoc analysis of clinical trial; USA; published } \\
\text { in } 2002\end{array}$ & 10904 & 46.4 & 100 & $\begin{array}{l}\text { Participants were men without definite evidence of clinical CHD but with above-average risk for death due } \\
\text { to CHD because of high blood pressure, elevated serum cholesterol levels, and/or cigarette smoking in the } \\
\text { Multiple Risk Factor Intervention Trial }\end{array}$ \\
\hline Orth-Gomer $2000^{32}$ & Prospective cohort study; Sweden; 1991-1997 & 292 & 55.8 & 0 & $\begin{array}{l}\text { Participants were female acute MI or unstable angina patients aged } 30-65 \text { years in the Stockholm Female } \\
\text { Coronary Risk Study }\end{array}$ \\
\hline Panagiotakos $2008^{3}$ & Prospective cohort study; Greece; 2003-2004 & 2090 & 66.7 & 75.9 & Participants were patients hospitalised with ACS in the GREECS study \\
\hline Quinones $2014^{33}$ & Prospective cohort study; Germany; 2000-2010 & 3766 & 28 to 74 & 75.4 & $\begin{array}{l}\text { Participants were patients with first episode of MI in Germany who survived longer than } 28 \text { days in the } \\
\text { MONICA/KORA-myocardial infarction registry }\end{array}$ \\
\hline Samanci $2004^{12}$ & Prospective cohort study; Turkey; 1995-2001 & 147 & 62.6 & 53 & $\begin{array}{l}\text { Participants were patients with first ischaemic stroke aged } 18 \text { and above who were admitted to Akdeniz } \\
\text { University Hospital }\end{array}$ \\
\hline Schultz $2017^{34}$ & Prospective cohort study; USA; 2003-2015 & 6051 & 63 & 64 & $\begin{array}{l}\text { Participants were patients who underwent cardiac catheterisation for suspected or known coronary artery } \\
\text { disease in the Emory Cardiovascular Biobank }\end{array}$ \\
\hline Sorlie $2004^{25}$ & Prospective cohort study; USA; $1973-1989$ & $\begin{array}{l}\text { Approximately } \\
700000\end{array}$ & $\geq 25$ & - & Participants were individuals aged 25 and above in the US National Longitudinal Mortality Study \\
\hline Strand $2004^{37}$ & Prospective cohort study; Norway; $1974-2000$ & 44684 & 42 & 50.8 & Participants were individuals without history of heart disease aged 35 to 49 years in Norway \\
\hline Vujcic $2014^{9}$ & Prospective cohort study; Belgrade; 2002-2011 & 135 & 57.8 & 75.6 & $\begin{array}{l}\text { Participants were patients admitted to the coronary care unit of the Institute of Cardiovascular Diseases, } \\
\text { Clinical Centre of Serbia due to MI }\end{array}$ \\
\hline Wolinsky $2009^{40}$ & Prospective cohort study; USA; 1993-2005 & 5511 & 77 & 38 & $\begin{array}{l}\text { Participants were individuals aged } 70 \text { and above in the Survey on Assets and Health Dynamics among the } \\
\text { Oldest Old }\end{array}$ \\
\hline Xie $2016^{2}$ & Prospective cohort study; China; 2002-2012 & 1739 & 57.7 & 35.8 & $\begin{array}{l}\text { Participants were individuals from } 11 \text { villages in Beijing drawn from the original cohort of the People's } \\
\text { Republic of China-United States of America Collaborative Study of Cardiovascular and Cardiopulmonary } \\
\text { Epidemiology }\end{array}$ \\
\hline Yokoyama $2014^{10}$ & $\begin{array}{l}\text { Prospective cohort study; Japan; Published } \\
\text { in } 2014\end{array}$ & 354 & 63 & 100 & Participants were men who had acute MI \\
\hline
\end{tabular}

supplementary figure 4) and stroke mortality (OR 2.33, 95\% CI 1.11 to $4.89, \mathrm{I}^{2}=0 \%, \mathrm{P}=0.03, \mathrm{n}=1$ ) (online supplementary figure 6). Widowed participants of either sex in these studies did not have increased CHD mortality or stroke mortality (online supplementary figures 5 and 7).

\section{Cardiovascular risks in general population}

Unmarried participants were 1.4 times more likely to develop CVD (OR 1.42, 95\% CI 1.00 to $2.01, \mathrm{P}=0.05, \mathrm{n}=1$ ) (figure $3 \mathrm{C}$ ) with a slight increase in the odds of developing CHD (OR 1.16, $95 \%$ CI 1.04 to $1.28, \mathrm{I}^{2}=69 \%, \mathrm{P}=0.006, \mathrm{n}=8$ ) (figure $3 \mathrm{~A}$ ), but no difference was observed for incident stroke $(\mathrm{P}=0.15, \mathrm{n}=4)$ compared with married participants (figure $3 \mathrm{~B}$ ).

Results for divorced and widowed patients is shown in table 3. Being divorced in both sexes were 1.3 times more likely to develop CHD (OR 1.35, 95\% CI 1.20 to $1.53, \mathrm{I}^{2}=0 \%$, $\mathrm{P}<0.001, \mathrm{n}=3$ ) (online supplementary figure 10) with a slight increase in incident stroke odds (OR 1.15, 95\% CI 1.01 to 1.29 , $\mathrm{I}^{2}=53 \% \mathrm{P}=0.02, \mathrm{n}=4$ ) (online supplementary figure 12 ). In contrast, widowed participants were more likely to develop a stroke (OR 1.16, 95\% CI 1.09 to $1.23, \mathrm{I}^{2}=0 \%, \mathrm{P}<0.001, \mathrm{n}=4$ ) (online supplementary figure 13 ) but not $\mathrm{CHD}(\mathrm{P}=0.07, \mathrm{n}=1$ ) (online supplementary figure 11).

\section{Mortality in CVD population (MI and stroke)}

Results for participants with CVD, for the whole population and stratified by gender are summarised in figure 4 and table 4 . Mortality was significantly higher for unmarried patients who sustained a myocardial infarction (OR 1.42, 95\% CI 1.14 to $1.76, \mathrm{I}^{2}=83 \%, \mathrm{P}<0.002, \mathrm{n}=11$ ) (figure $4 \mathrm{~A}$ ). Being divorced is 


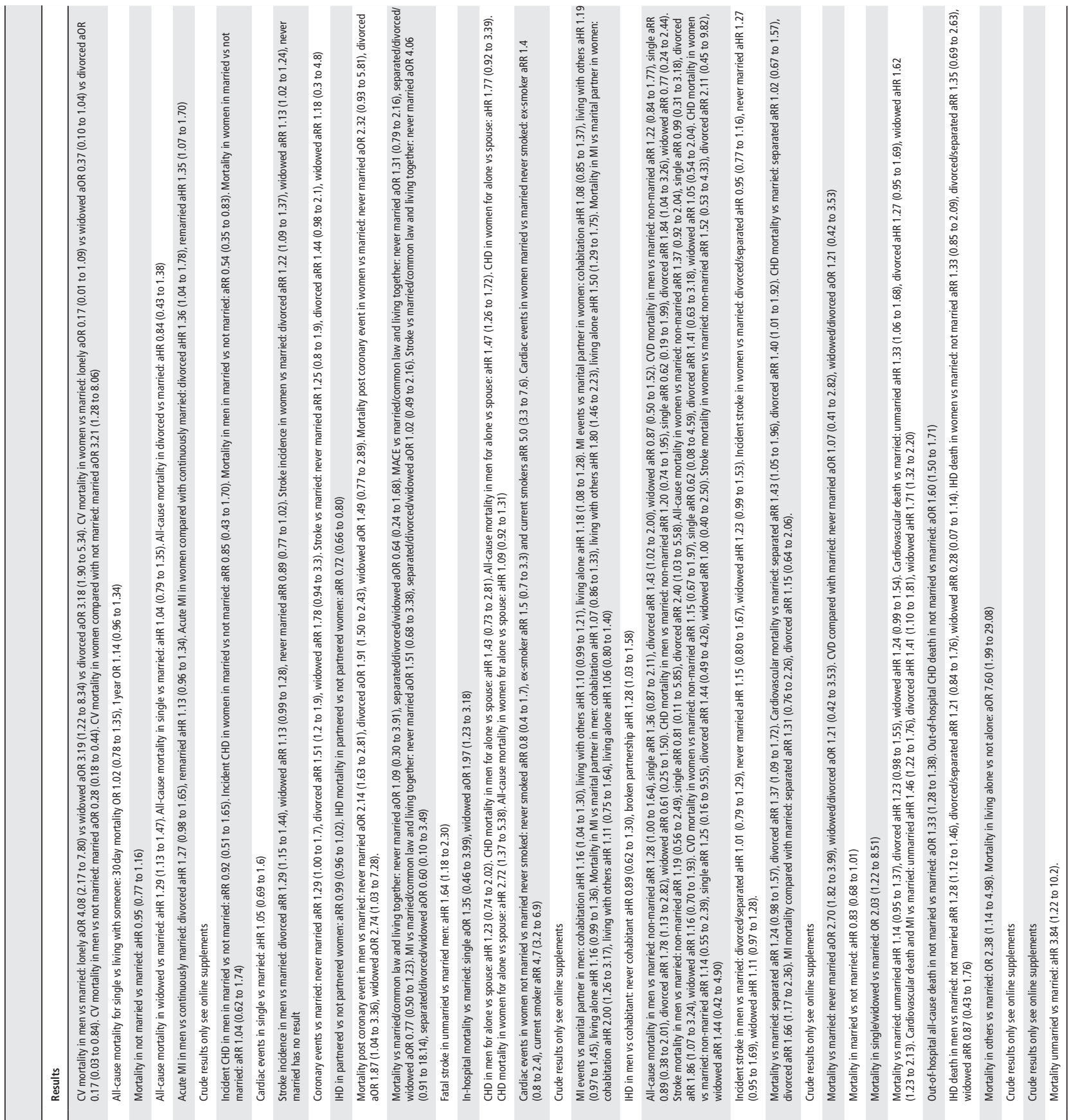

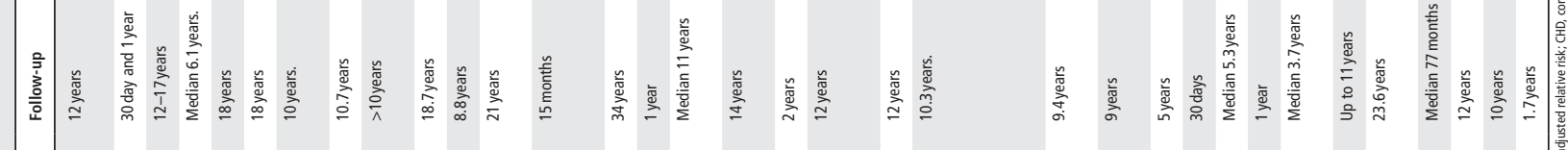

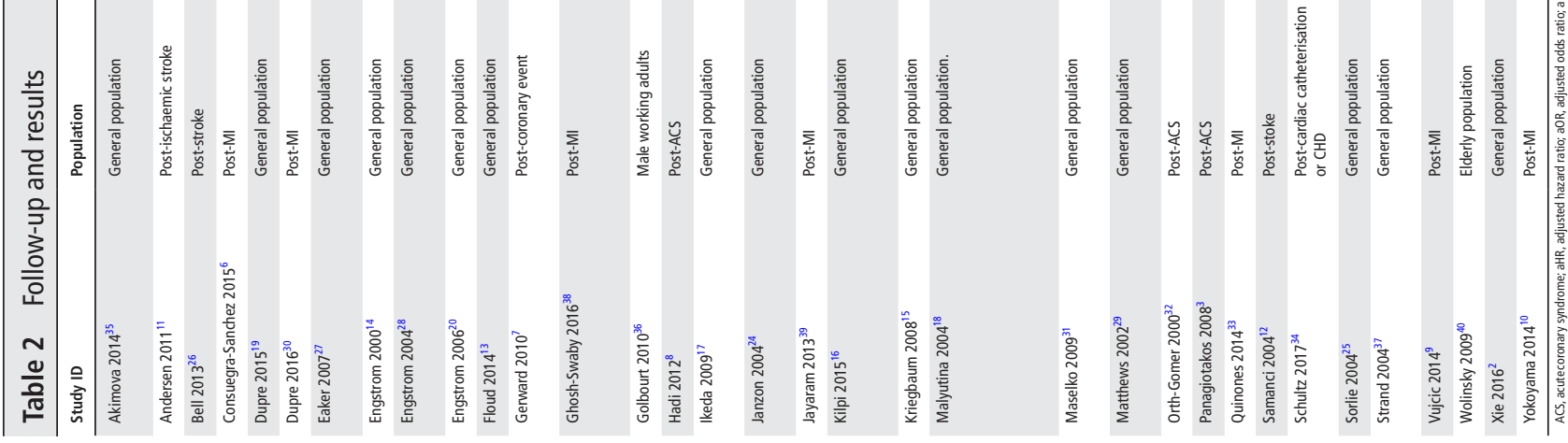


Table 3 Risk of adverse outcomes considering marital status in the general population

\begin{tabular}{|c|c|c|c|c|c|c|c|}
\hline Outcome & Marital status and subgroups & Studies & $\begin{array}{l}\text { No. of participants (not } \\
\text { applicable, (NA) for studies } \\
\text { with no crude result available) }\end{array}$ & Odds ratio $(95 \% \mathrm{Cl})$ & $\begin{array}{l}\text { Overall effect, } P \\
\text { values }\end{array}$ & Heterogeneity, $I^{2} \%$ & $\begin{array}{l}\text { Subgroup differences } \\
\text { between men only and } \\
\text { women only }\left(\mathrm{P} \text { values, } \mathrm{I}^{2}\right)\end{array}$ \\
\hline \multirow[t]{15}{*}{ CHD death } & Unmarried vs married & & & & & & \\
\hline & All & 5 & $>766272$ (2 NA) & $1.43(1.28$ to 1.60$)$ & $<0.001$ & 57 & \\
\hline & Men only & 3 & $>16137(1 \mathrm{NA})$ & $1.28(1.13$ to 1.45$)$ & $<0.001$ & 0 & $0.35,0 \%$ \\
\hline & Women only & 4 & $>750135$ (1 NA) & 1.44 (1.16 to 1.78$)$ & $<0.001$ & 25 & \\
\hline & Men and women & 1 & NA & 1.60 (1.50 to 1.71$)$ & $<0.001$ & - & \\
\hline & Divorced vs married & & & & & & \\
\hline & All & 3 & $>10378$ (2 NA) & 1.33 (1.04 to 1.70$)$ & 0.02 & 0 & \\
\hline & Men only & 3 & $>6139$ (2 NA) & $1.32(1.00$ to 1.73$)$ & 0.05 & 0 & $0.90,0 \%$ \\
\hline & Women only & 2 & $>4239$ (1 NA) & 1.37 (0.78 to 2.43 ) & 0.27 & 0 & \\
\hline & Widowed vs married & & & & & & \\
\hline & All & 2 & $>10105(1 \mathrm{NA})$ & 0.78 (0.48 to 1.25$)$ & 0.29 & 0 & \\
\hline & Men only & 2 & $>5940$ (1 NA) & 0.50 (0.19 to 1.34$)$ & 0.17 & 16 & $0.30,8.7 \%$ \\
\hline & Women only & 2 & $>4165$ (1 NA) & $0.92(0.52$ to 1.60$)$ & 0.76 & 0 & \\
\hline & Separated vs married & & & & & & \\
\hline & Men only & 1 & 10330 & 1.31 (0.76 to 2.26 ) & 0.33 & - & \\
\hline \multirow[t]{12}{*}{ Stroke death } & Unmarried vs married & & & & & & \\
\hline & All & 2 & $>11404$ (1 NA) & 1.55 (1.16 to 2.08 ) & 0.003 & 0 & \\
\hline & Men only & 2 & $>6485$ (1 NA) & 1.55 (1.15 to 2.11$)$ & 0.005 & 0 & $0.97,0 \%$ \\
\hline & Women only & 1 & 4919 & 1.52 (0.53 to 4.34$)$ & 0.43 & - & \\
\hline & Divorced vs married & & & & & & \\
\hline & All & 1 & 10724 & 2.33 (1.11 to 4.89 ) & 0.03 & 0 & \\
\hline & Men only & 1 & 6485 & 2.40 (1.03 to 5.59$)$ & 0.04 & - & $0.89,0 \%$ \\
\hline & Women only & 1 & 4239 & 2.11 (0.45 to 9.86 ) & 0.34 & - & \\
\hline & Widowed vs married & & & & & & \\
\hline & All & 1 & 10105 & 1.09 (0.39 to 3.09$)$ & 0.86 & 0 & \\
\hline & Men only & 1 & 5940 & 0.55 (0.08 to 3.85 ) & 0.55 & - & $0.41,0 \%$ \\
\hline & Women only & 1 & 4165 & 1.44 (0.42 to 4.92$)$ & 0.56 & - & \\
\hline \multirow[t]{14}{*}{ CVD death } & Unmarried vs married & & & & & & \\
\hline & All & 2 & $>11404$ (1 NA) & 1.20 (0.55 to 2.65$)$ & 0.65 & 89 & \\
\hline & Men only & 2 & $>6485$ (1 NA) & 2.07 (0.72 to 5.94$)$ & 0.17 & 92 & $0.16,49.4 \%$ \\
\hline & Women only & 2 & $>4919$ (1 NA) & 0.63 (0.18 to 2.26 ) & 0.48 & 83 & \\
\hline & Divorced vs married & & & & & & \\
\hline & All & 3 & $>20769$ (1 NA) & 1.56 (0.95 to 2.56$)$ & 0.08 & 73 & \\
\hline & Men only & 3 & $>16530$ (1 NA) & 1.93 (1.22 to 3.06$)$ & 0.005 & 71 & $0.25,24.7 \%$ \\
\hline & Women only & 2 & $>4239$ (1 NA) & 0.56 (0.07 to 4.37$)$ & 0.58 & 80 & \\
\hline & Widowed vs married & & & & & & \\
\hline & All & 2 & $>10105$ (1 NA) & 0.96 (0.43 to 2.16$)$ & 0.93 & 69 & \\
\hline & Men only & 2 & $>5940$ (1 NA) & 1.38 (0.27 to 6.99$)$ & 0.70 & 84 & $0.48,0 \%$ \\
\hline & Women only & 2 & $>4165$ (1 NA) & 0.70 (0.26 to 1.90$)$ & 0.48 & 57 & \\
\hline & Separated vs married & & & & & & \\
\hline & Men only & 1 & 10330 & 1.43 (1.05 to 1.95$)$ & 0.02 & - & \\
\hline \multirow[t]{15}{*}{ All-cause mortality } & Unmarried vs married & & & & & & \\
\hline & All & 4 & $>33145$ (2 NA) & 1.31 (1.19 to 1.45$)$ & $<0.001$ & 42 & \\
\hline & Men only & 3 & $>16137$ (1 NA) & 1.45 (1.26 to 1.66$)$ & $<0.001$ & 11 & $0.01,83.3 \%$ \\
\hline & Women only & 3 & $>17008$ (1 NA) & $1.12(0.96$ to 1.30$)$ & 0.16 & 0 & \\
\hline & Men and women & 1 & NA & 1.33 (1.28 to 1.38$)$ & $<0.001$ & - & \\
\hline & Divorced vs married & & & & & & \\
\hline & All & 2 & $>10378$ (1 NA) & 1.43 (1.20 to 1.71$)$ & $<0.001$ & 0 & \\
\hline & Men only & 2 & $>6139$ (1 NA) & 1.39 (1.15 to 1.68$)$ & $<0.001$ & 0 & $0.33,0 \%$ \\
\hline & Women only & 1 & 4239 & 1.86 (1.07 to 3.24$)$ & 0.03 & - & \\
\hline & Widowed vs married & & & & & & \\
\hline & All & 1 & 10105 & 1.02 (0.70 to 1.48$)$ & 0.93 & 0 & \\
\hline & Men only & 1 & 5940 & 0.87 (0.50 to 1.52 ) & 0.62 & - & $0.45,0 \%$ \\
\hline & Women only & 1 & 4165 & 1.16 (0.70 to 1.93$)$ & 0.57 & - & \\
\hline & Separated vs married & & & & & & \\
\hline & Men only & 1 & NA & 1.24 (0.98 to 1.57 ) & 0.07 & - & \\
\hline \multirow[t]{2}{*}{ CVD events } & Unmarried vs married & & & & & & \\
\hline & Men and women & 1 & 1739 & 1.42 (1.00 to 2.01$)$ & 0.05 & - & \\
\hline
\end{tabular}




\begin{tabular}{|c|c|c|c|c|c|c|c|}
\hline Outcome & Marital status and subgroups & Studies & $\begin{array}{l}\text { No. of participants (not } \\
\text { applicable, (NA) for studies } \\
\text { with no crude result available) }\end{array}$ & Odds ratio $(95 \% \mathrm{Cl})$ & $\begin{array}{l}\text { Overall effect, } P \\
\text { values }\end{array}$ & Heterogeneity, $I^{2} \%$ & $\begin{array}{l}\text { Subgroup differences } \\
\text { between men only and } \\
\text { women only }\left(\mathrm{P} \text { values, } \mathrm{I}^{2}\right)\end{array}$ \\
\hline \multirow[t]{15}{*}{ CHD events } & Unmarried vs married & & & & & & \\
\hline & All & 8 & >1 011397 (2 NA) & 1.16 (1.04 to 1.28$)$ & 0.006 & 69 & \\
\hline & Men only & 5 & $>134152(2 \mathrm{NA})$ & $1.21(1.14$ to 1.30$)$ & $<0.001$ & 0 & $0.20,40.2 \%$ \\
\hline & Women only & 5 & $>867894(2 \mathrm{NA})$ & $1.10(0.96$ to 1.26$)$ & 0.19 & 41 & \\
\hline & Men and women & 1 & 9351 & 1.05 (0.69 to 1.60$)$ & 0.82 & - & \\
\hline & Divorced vs married & & & & & & \\
\hline & All & 3 & $>12812$ (1 NA) & 1.35 (1.20 to 1.53$)$ & $<0.001$ & 0 & \\
\hline & Men only & 3 & $>5389$ (1 NA) & 1.35 (1.18 to 1.55$)$ & $<0.001$ & 0 & $0.97,0 \%$ \\
\hline & Women only & 1 & NA & 1.36 (1.04 to 1.78$)$ & 0.02 & - & \\
\hline & Widowed vs married & & & & & & \\
\hline & Men only & 1 & 4754 & 1.78 (0.95 to 3.34$)$ & 0.07 & - & \\
\hline & Remarried vs married & & & & & & \\
\hline & All & 1 & NA & 1.21 (1.02 to 1.44$)$ & 0.03 & 33 & \\
\hline & Men only & 1 & NA & 1.13 (0.96 to 1.34$)$ & 0.15 & - & $0.22,33.1 \%$ \\
\hline & Women only & 1 & NA & 1.35 (1.07 to 1.70$)$ & 0.01 & - & \\
\hline \multirow[t]{15}{*}{ Stroke events } & Unmarried vs married & & & & & & \\
\hline & All & 4 & $>19829$ (2 NA) & 1.23 (0.93 to 1.63$)$ & 0.15 & 78 & \\
\hline & Men only & 3 & $>8640(2 \mathrm{NA})$ & 1.01 (0.81 to 1.26$)$ & 0.93 & 41 & $0.21,35 \%$ \\
\hline & Women only & 1 & 8268 & 1.27 (0.95 to 1.69$)$ & 0.10 & - & \\
\hline & Men and women & 1 & 2921 & 1.93 (1.34 to 2.78 ) & $<0.001$ & - & \\
\hline & Divorced vs married & & & & & & \\
\hline & All & 4 & $>26843(1 \mathrm{NA})$ & 1.15 (1.02 to 1.29$)$ & 0.02 & 53 & \\
\hline & Men only & 3 & $>14532$ (1 NA) & 1.22 (1.02 to 1.46$)$ & 0.03 & 46 & $0.47,0 \%$ \\
\hline & Women only & 2 & $>9279$ (1 NA) & 1.09 (0.86 to 1.39$)$ & 0.47 & 77 & \\
\hline & Men and women & 1 & 3032 & 0.94 (0.62 to 1.43$)$ & 0.77 & - & \\
\hline & Widowed vs married & & & & & & \\
\hline & All & 4 & $>29692$ (1 NA) & 1.16 (1.09 to 1.23$)$ & $<0.001$ & 0 & \\
\hline & Men only & 3 & $>13728$ (1 NA) & 1.16 (1.03 to 1.29$)$ & 0.01 & 0 & $0.69,0 \%$ \\
\hline & Women only & 2 & $>10948$ (1 NA) & 1.12 (1.04 to 1.22$)$ & 0.004 & 0 & \\
\hline & Men and women & 1 & 5016 & 1.33 (1.12 to 1.57$)$ & $<0.001$ & - & \\
\hline
\end{tabular}

CHD, coronary heart disease; CVD, cardiovascular disease.

not associated with increased mortality after $\mathrm{MI}(\mathrm{P}=0.13, \mathrm{n}=3)$ (figure 4B). For widowed participants, the increased odds of death post-MI was almost 1.7 times (OR 1.68, 95\% CI 1.30 to $2.17, \mathrm{I}^{2}=85 \%, \mathrm{P}<0.001, \mathrm{n}=4$ ) (figure $4 \mathrm{C}$ ).

After a stroke, there was no difference in mortality between unmarried and married participants $(\mathrm{P}=0.47, \mathrm{n}=3$ ) (online supplementary figure 14).

\section{Mortality in post-cardiac catheterisation population}

In the post-cardiac catheterisation population consisting of a heterogeneous cohort of patients under elective investigation for possible coronary artery disease or acutely following a myocardial infarction, there was no significant difference in all-cause mortality in the unmarried, divorced and widowed groups when compared with married participants with adjusted hazard ratio (aHR) 1.14 (95\% CI 0.95 to 1.37 ), aHR 1.23 (95\% CI 0.98 to 1.55), and aHR 1.24 (95\% CI 0.99 to 1.54$)$, respectively. Both the unmarried and widowed participants were at increased risk of cardiovascular death, corresponding aHR 1.33 (95\% CI 1.06 to 1.68$)$ and aHR $1.62(95 \%$ CI 1.23 to 2.13$)$, respectively, but the risk was not significant in divorced participants (aHR 1.27, $95 \%$ CI 0.95 to 1.69 ).

\section{DISCUSSION}

To the best of our knowledge, this is the first evidence synthesis to quantify the evidence base using meta-analysis to evaluate the relationship between marital status and cardiovascular disease. Our analysis showed that compared with married individuals, being unmarried was associated with increased CHD and both CHD and stroke mortality in the general population. Similarly, we observed greater odds of death from CHD and stroke in divorced compared with married individuals. Finally, in the widowed population only stroke incidence was elevated with similar odds in both sexes. Our analysis also describes important differences in prognosis with regard to mortality according to marital status in patients with incident cardiovascular disease. In participants who suffered a myocardial infarction, being unmarried was associated with greater odds of mortality compared with a married individual, with a non-significant trend in widowed or divorced individuals. In our analysis, no significant gender effect was observed for the association between marital status and developing CVD and death from CVD in any groups of participants, although differences in total mortality were noted.

We have built on the current understanding of marital status and adverse outcomes in several ways. First, a previous meta-analysis of 53 studies demonstrated higher all-cause mortality in never married, divorced and widowed married versus married individuals, ${ }^{41}$ but the study did not explore any specific causes of death or cardiovascular disease. A more recent review published by Manfredini et al describes the improved health status and reduced cardiovascular risk with married status but it did not quantify the relationships with meta-analysis. ${ }^{42}$ Our updated review with 34 studies has built on the findings of these reviews to quantify the relationship between marital status and CVD while considering the unmarried, divorced and widowed status of the populations assessed. 
Several mechanisms have been suggested to account for the observed protective effect of marital status on CVD, especially in men. Social causation theory suggests that individuals benefit from spousal support. ${ }^{43}$ For example, living with another person allows earlier recognition and response to warning symptoms, ${ }^{1625}$ especially if a myocardial infarction becomes instantly disabling. ${ }^{25}$ Studies have reported that unmarried patients had longer delays in seeking medical help ${ }^{781644}$ and longer total ischaemic times ${ }^{44}$ which directly influences both the timing and proportion of participants being treated with either thrombolysis or invasive cardiac procedures that reduce mortality. ${ }^{78}$ In addition, spouses, particularly wives, encourage concordant health behaviour such as a healthy lifestyle ${ }^{13} 161945$ and adherence to treatment ${ }^{513161945}$ that promote cardiovascular health. In contrast, marital dissolution is noted to affect the health behaviour mentioned above negatively. ${ }^{29}$ Moreover, Wu et al reported that compared with married individuals, unmarried individuals were twice more likely to be non-adherent to their prescribed medications which was the strongest predictor of better outcome in their study. ${ }^{45}$ There are greater financial resources, especially in households with a dual income, making better healthcare more accessible. ${ }^{13}{ }^{1630}$ Furthermore, one of the benefits of being married or with a partner may be increased participation in cardiac rehabilitation which improves outcomes after cardiovascular disease. ${ }^{46}$

Stress-related theory suggests that partner loss or poorquality relationships may have a negative impact on the economic, behavioural and emotional well-being of an individual which may reduce one's ability to prevent, detect and treat illness. ${ }^{33}$ Biologically, stress may ultimately worsen cardiovascular risk factors such as hypertension, reduced heart rate variability, impaired vagal tone, hyperlipidaemia, diabetes and the progression of atherosclerosis. ${ }^{929} 32$ The buffering hypothesis suggests that informational or emotional resources from a spouse promote adaptive behaviour and may reduce excessive neuroendocrine response to acute or chronic stressors. ${ }^{1735}$ This translates into a decrease in progression of atherosclerosis and other pathological processes, thus reducing the risk of CVD.

Furthermore, selection theory has been introduced which assumes that individuals with poor health are less likely to establish or maintain long-term relationships such as marriage. ${ }^{5} 33$ Also, Floud et al suggested the possibility that healthy women may be less likely to divorce, ${ }^{13}$ although Akimova et al reported that divorced and single women were more highly educated and had a higher qualified occupation which results in greater financial independence and better quality of life. ${ }^{35}$

In widowed populations, there is less variation in CVD incidence and mortality between sexes with some studies showing women do more poorly than men. Vujcic et al showed that the proportion of women who lived alone increased with age while the proportion of men who lived alone decreased with age. ${ }^{9}$ Possible explanations include women tend to be younger than their husbands and have a longer life expectancy. ${ }^{9}$ Thus, it is postulated that widowed women tend to be older and more support is needed to meet their healthcare requirement. This study has several strengths and limitations. This is the largest study to date with a sample size of more than 2 million compared with the smaller sample sizes of previous reviews. ${ }^{4142}$ We were able to quantify the risk with meta-analysis which was not performed in the previous studies. ${ }^{42}$ In terms of generalisability, the current review included populations from various age

Table 4 Risk of adverse outcomes considering marital status in specific groups of participants

\begin{tabular}{|c|c|c|c|c|c|c|c|}
\hline Outcome & Marital status and subgroups & Studies & $\begin{array}{l}\text { No. of participants (not applicable, } \\
\text { (NA) for studies with no crude } \\
\text { result available) }\end{array}$ & Odds ratio $(95 \% \mathrm{Cl})$ & Overall effect, $P$ value & Heterogeneity, $1^{2} \%$ & $\begin{array}{l}\text { Subgroup differences } \\
\text { between men only and } \\
\text { women only }\left(\mathrm{P} \text { value, } \mathrm{I}^{2}\right)\end{array}$ \\
\hline \multirow[t]{4}{*}{ Mortality post stroke } & Unmarried vs married & & & & & & \\
\hline & All & 3 & 29419 & 1.08 (0.88 to 1.32$)$ & 0.47 & 43 & \\
\hline & Women only & 1 & 3156 & 0.95 (0.77 to 1.17$)$ & 0.62 & - & \\
\hline & Men and women & 2 & 26263 & 1.24 (0.83 to 1.84$)$ & 0.29 & 24 & \\
\hline \multirow[t]{15}{*}{ Mortality post MI } & Unmarried vs married & & & & & & \\
\hline & All & 11 & $>21456$ (3 NA) & $1.42(1.14$ to 1.76$)$ & 0.002 & 83 & \\
\hline & Men only & 2 & $>2453$ (1 NA) & 1.76 (1.24 to 2.49$)$ & 0.001 & 80 & $0.56,0 \%$ \\
\hline & Women only & 2 & $>374$ (1 NA) & 1.38 (0.67 to 2.86$)$ & 0.38 & 61 & \\
\hline & Men and women & 9 & $>18629$ (2 NA) & 1.35 (1.00 to 1.83 ) & 0.05 & 84 & \\
\hline & Divorced vs married & & & & & & \\
\hline & All & 3 & $>4158$ (1 NA) & $1.36(0.92$ to 2.01$)$ & 0.13 & 85 & \\
\hline & Men only & 1 & 2525 & 1.91 (1.50 to 2.43$)$ & $<0.001$ & - & $0.95,0 \%$ \\
\hline & Women only & 1 & 447 & 1.87 (1.04 to 3.36$)$ & 0.04 & - & \\
\hline & Men and women & 2 & $>1186$ (1 NA) & $1.08(0.95$ to 1.22$)$ & 0.23 & 0 & \\
\hline & Widowed vs married & & & & & & \\
\hline & All & 4 & $>9171$ (1 NA) & 1.68 (1.30 to 2.17$)$ & $<0.001$ & 85 & \\
\hline & Men only & 1 & 2136 & 1.49 (0.77 to 2.89 ) & 0.24 & - & $0.31,2.3 \%$ \\
\hline & Women only & 1 & 368 & 2.74 (1.03 to 7.28$)$ & 0.04 & - & \\
\hline & Men and women & 3 & $>6667$ (1 NA) & 1.65 (1.24 to 2.20$)$ & $<0.001$ & 92 & \\
\hline \multirow[t]{4}{*}{ MI post MI } & Unmarried vs married & & & & & & \\
\hline & All & 2 & 1964 & 0.72 (0.14 to 3.60$)$ & 0.69 & 77 & \\
\hline & Women only & 1 & 222 & 0.29 (0.08 to 1.08$)$ & 0.07 & - & \\
\hline & Men and women & 1 & 1742 & 1.51 (0.68 to 3.37$)$ & 0.31 & - & \\
\hline \multirow[t]{2}{*}{ MACE post MI } & Unmarried vs married & & & & & & \\
\hline & Men and women & 1 & 1742 & $1.31(0.79$ to 2.17$)$ & 0.29 & - & \\
\hline \multirow[t]{2}{*}{ Major bleeding post MI } & Unmarried vs married & & & & & & \\
\hline & Men and women & 1 & 1742 & $2.11(0.55$ to 8.10$)$ & 0.28 & - & \\
\hline \multirow[t]{2}{*}{ CVD post MI } & Unmarried vs married & & & & & & \\
\hline & Men and women & 1 & 1813 & 1.07 (0.41 to 2.81$)$ & 0.89 & - & \\
\hline
\end{tabular}


A) CHD death

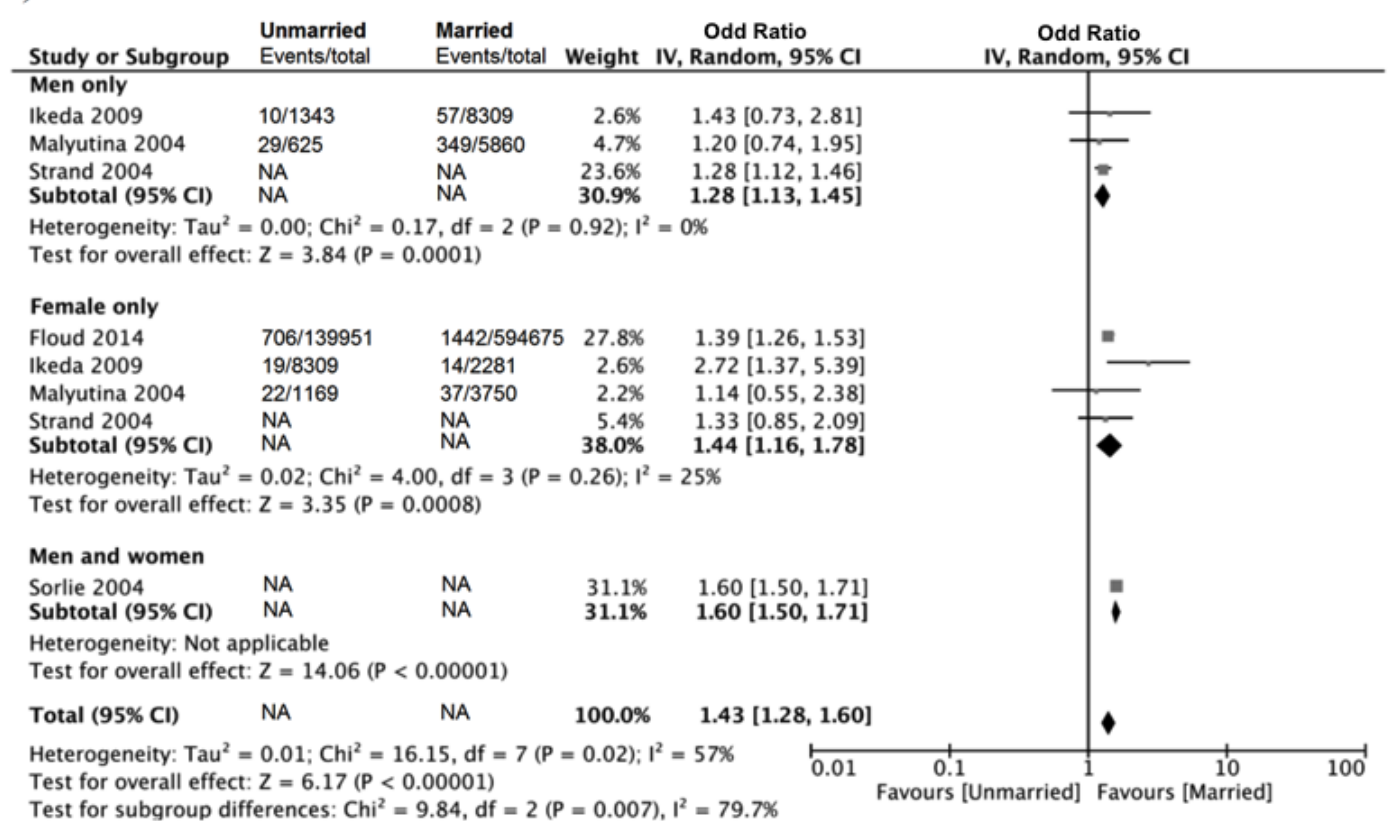

B) Stroke deaths

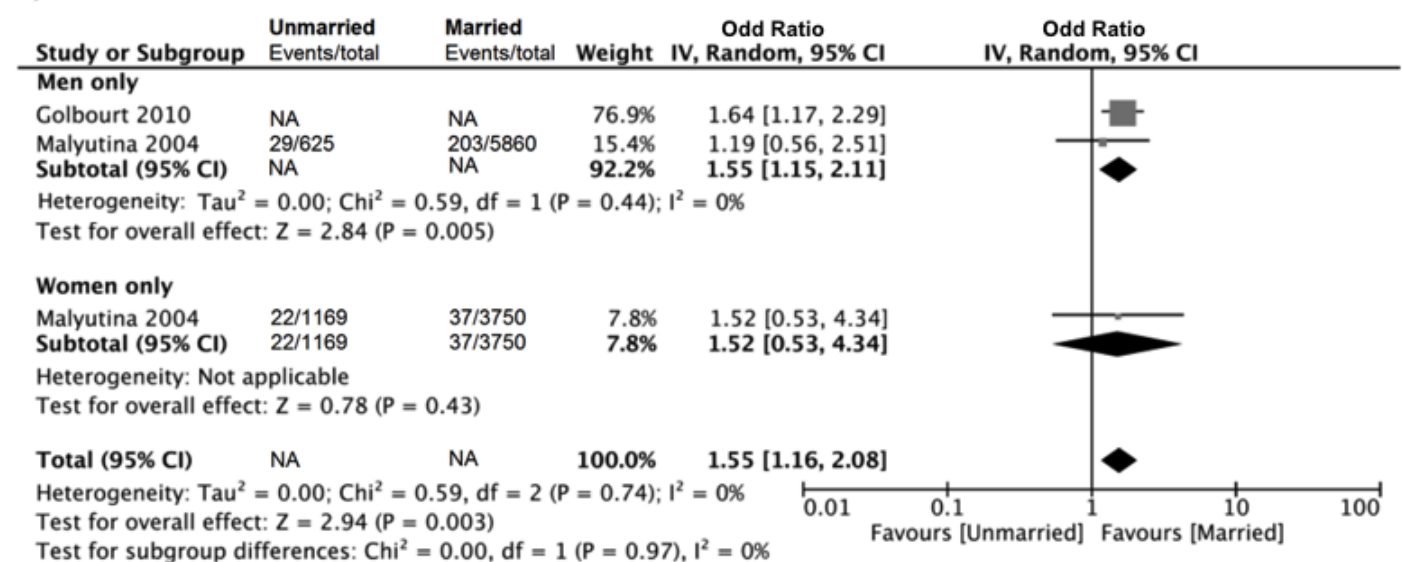

C) CVD death

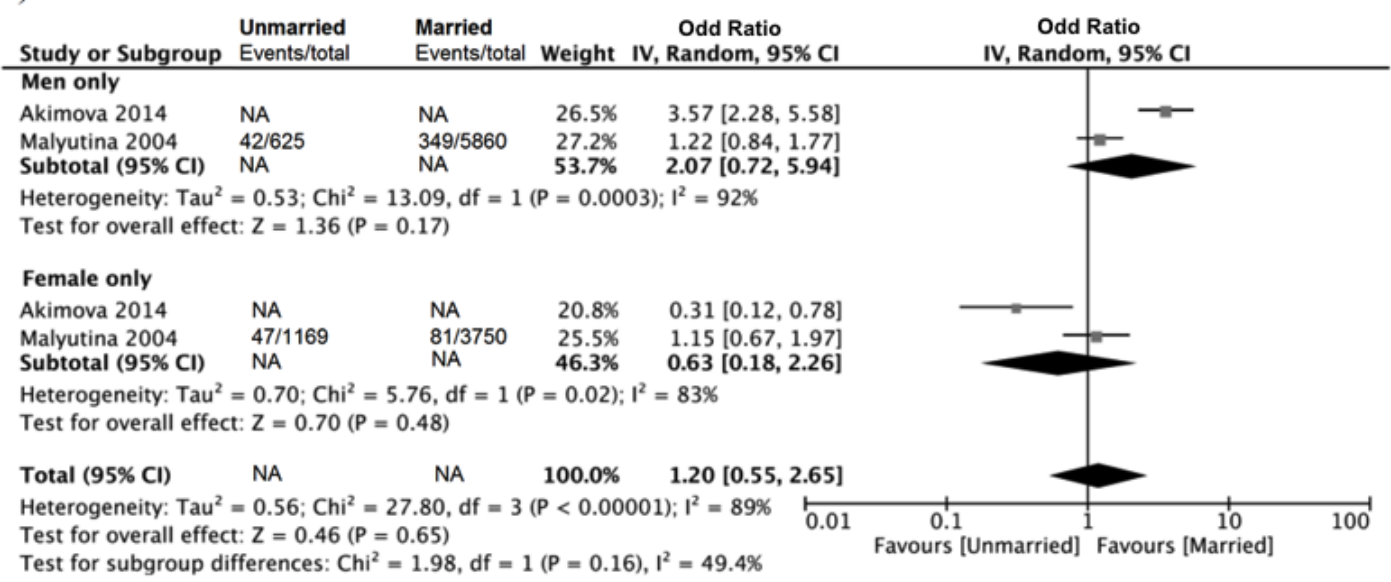

Figure 2 Forest plots of coronary heart disease (CHD), stroke and cardiovascular disease (CVD) deaths in unmarried vs married in the general population. 
A) CHD events

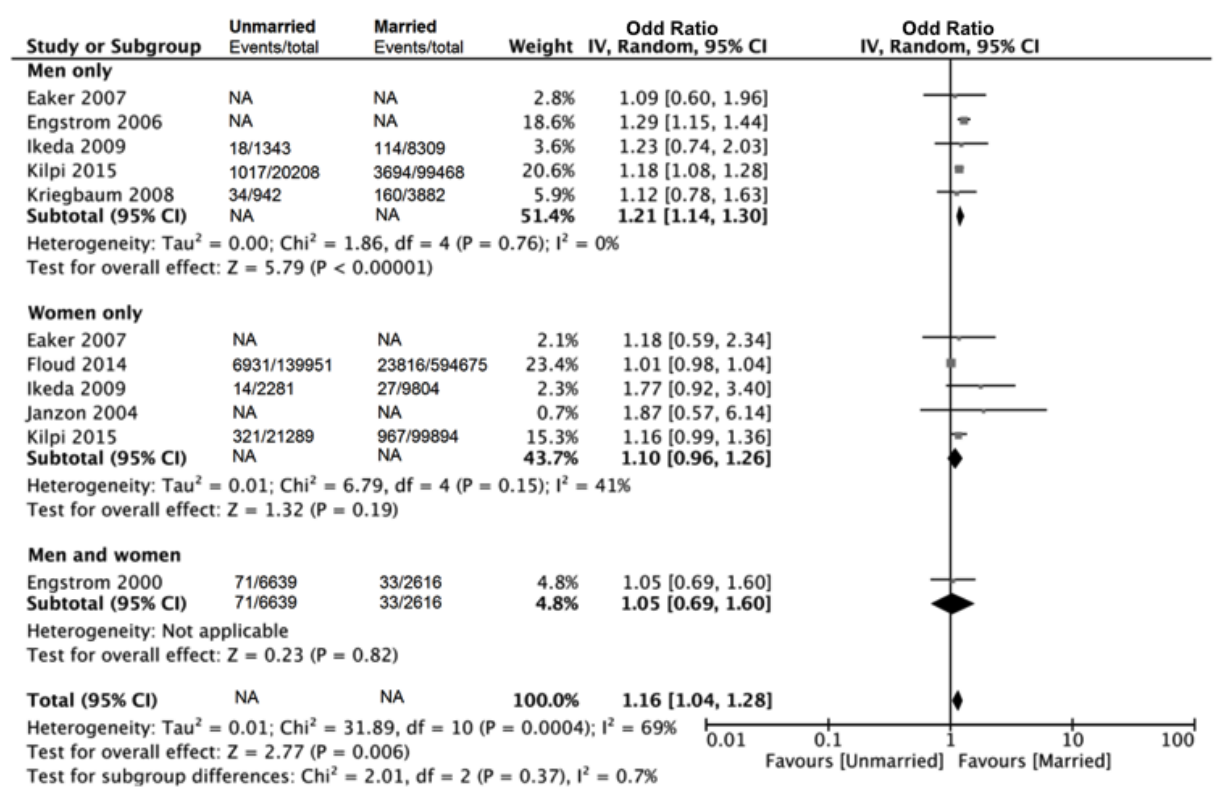

Figure 3 Forest plot of coronary heart disease (CHD), stroke and cardiovascular disease (CVD) events in unmarried vs married in the general population.

B) Stroke events

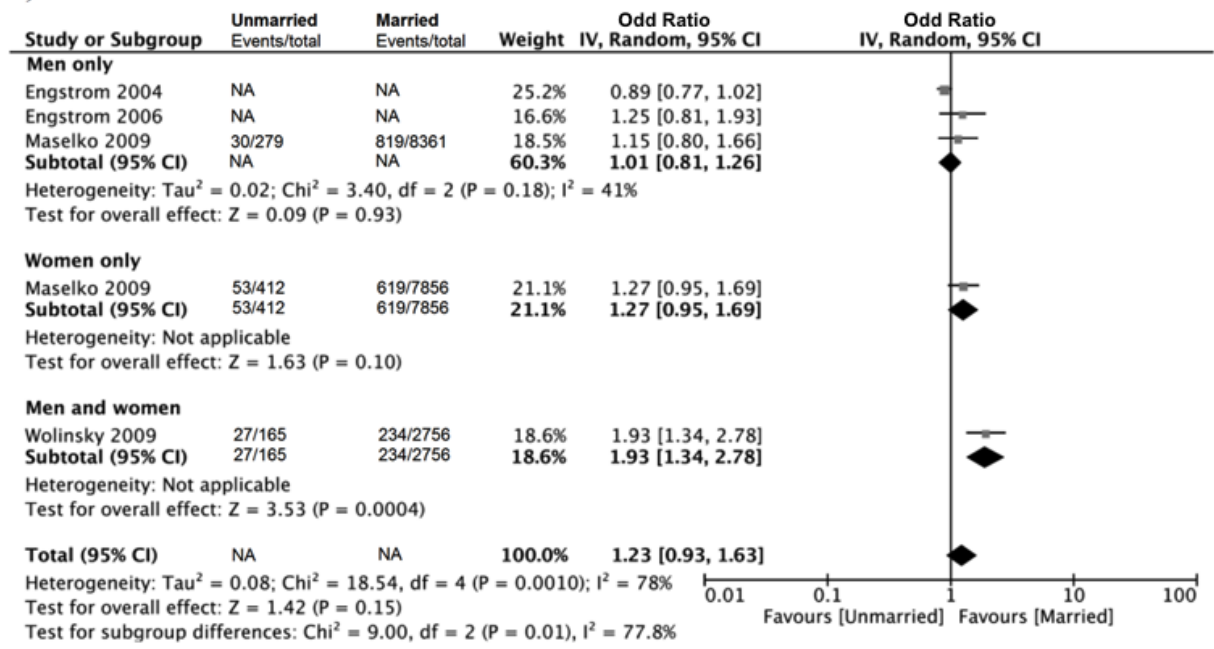

C) CVD events

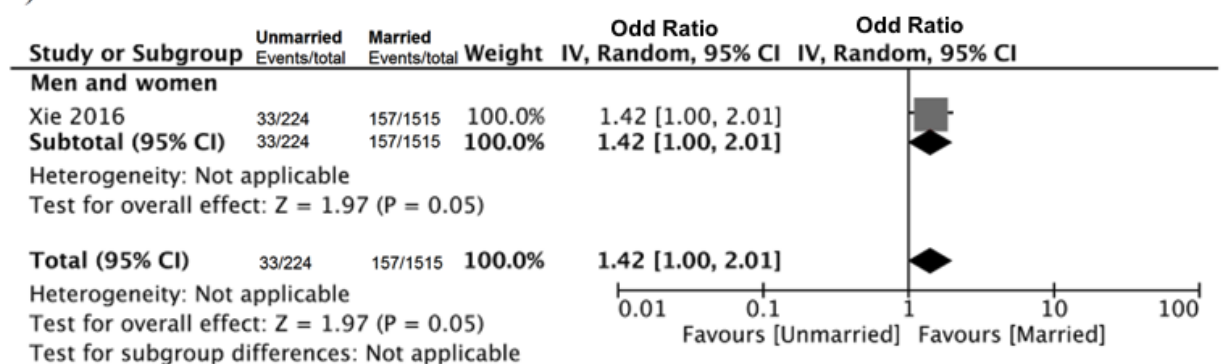

groups, ethnicities and geographic locations making the findings generalisable to different populations. We used a comprehensive search strategy of the literature and excluded case-control and retrospective studies to reduce the possibility of bias. Finally, results with the greatest extent of adjustments were used for the analysis in this study.
The major limitation of this study is the inconsistent variable adjustments across studies, which poses a risk of confounding. Adjustment for cardiovascular risk factors was often incomplete in many of the studies analysed, which may have influenced our result. In addition, this review is not an individual patient meta-analysis so information is solely derived from published 
A) Unmarried vs married.

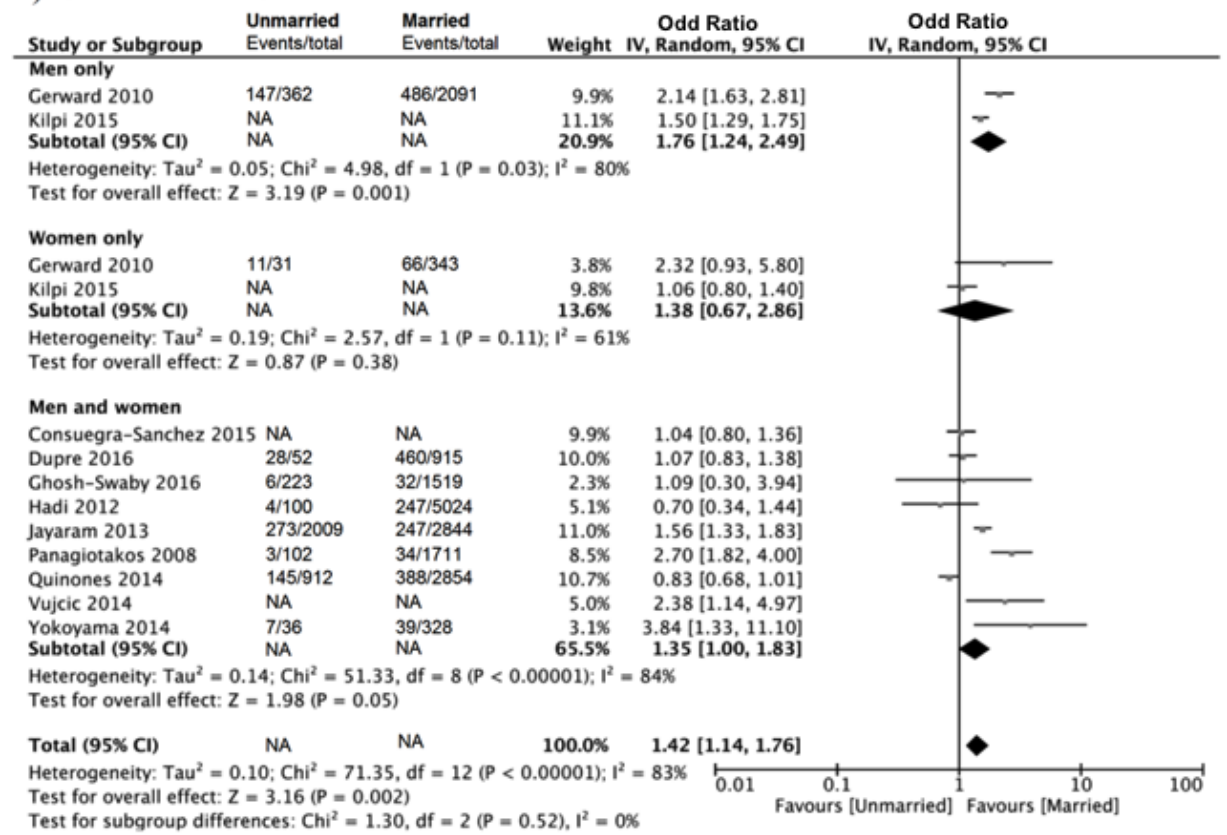

B) Divorced vs married.

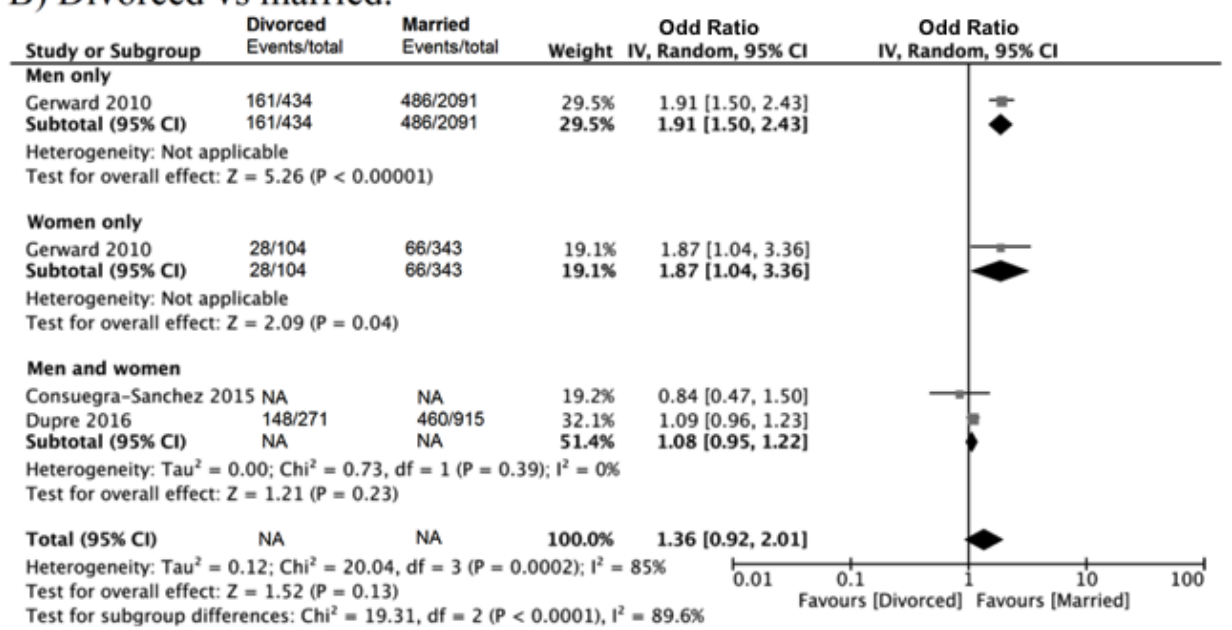

C) Widowed vs married.

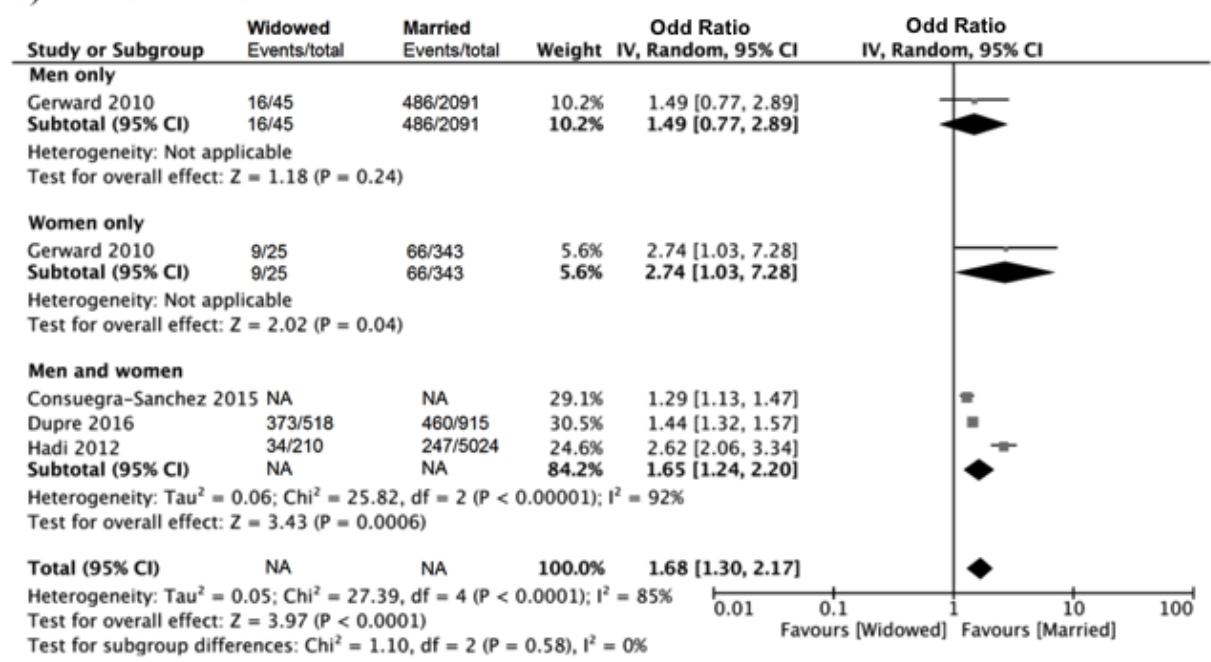

Figure 4 Forest plot of post myocardial infarction mortality by marital status. 
material. The lack of information on same-sex spouses and quality of marriage limit further insight into the impact of marriage. Moreover, heterogeneity exists across studies in terms of study methodology. For example, the definition of CVD varied across the studies and the follow-up period was inconsistent with some long-term studies ( $>15$ years of follow-up) where management might have changed over time. ${ }^{7} 1920303637$

Future work should focus on whether marital status is a surrogate marker of other adverse health behaviour or cardiovascular risk profiles that underlies our reported findings and whether targeted interventions should focus on such high-risk groups. The association between cohabitation/living with someone and CVD should be explored as it may be a confounding factor in this study. In Quinones et al, the replacement of marital status with cohabitation yielded the same protective effect although slightly less pronounced. ${ }^{33}$ Fournier $e t$ al suggested that having information of 'living alone' versus 'living with someone' instead of married versus not married would have been more useful. ${ }^{43}$

In conclusion, being married appears to be associated a lower cardiovascular mortality and incidence of CVD in a general population and mortality after myocardial infarction. While current evidence may demonstrate an association between marital status and mortality and CVD, lack of social support might be a mitigating factor. Future research should focus around whether marital status is a surrogate marker for other adverse health behaviour or cardiovascular risk profiles that underlies our reported findings, or whether marital status should be considered as a risk factor by itself.

\section{Key questions}

\section{What is already known about this subject?}

- While $80 \%$ of the risk for future cardiovascular disease (CVD) can be predicted from known cardiovascular risk factors such as hypertension, smoking and diabetes mellitus, the determinants for the remaining $20 \%$ risk remain unclear.

- One factor which may be associated with CVD is marital status and studies have reported inconsistent findings.

\section{What does this study add?}

- Our analysis showed that compared with married individuals, being unmarried was associated with increased all cause mortality, coronary heart disease (CHD) and both CHD and stroke mortality in the general population.

- Similarly, we observed a greater odds of death from CHD and stroke in divorced compared with married individuals.

- In the widowed population only stroke incidence was elevated with similar odds in both sexes.

\section{How might this impact on clinical practice?}

- These findings may suggest that marital status should be considered in the risk assessment for CVD.

\section{Author affiliations}

Keele Cardiovascular Research Group, Institute for Applied Clinical Science and Centre for Prognosis Research, Institute of Primary Care and Health Sciences, University of Keele and Academic Department of Cardiology, Royal Stoke Hospital, Stoke-on-Trent, UK

${ }^{2}$ University of Arizona College of Medicine-Phoenix, Phoenix, Arizona, USA ${ }^{3}$ Department of Cardiology and Kolling Institute, Royal North Shore Hospital, St Leonards and Macquarie University, Sydney, New South Wales, Australia ${ }^{4}$ Keele Cardiovascular Research Group, Institute for Applied Clinical Science and Centre for Prognosis Research, Institute of Primary Care and Health Sciences, University of Keele, Keele, UK
${ }^{5}$ Academic Department of Obstetrics and Gynaecology, Royal Stoke Hospital, Stokeon-Trent, UK

${ }^{6}$ Department of Cardiology, King Fahd Armed Forces Hospital, Jeddah, Saudi Arabia Institute of Applied Health Sciences, University of Aberdeen, Aberdeen, UK

Acknowledgements We acknowledge the ASPIRE Summer Studentship programme at Keele University for the support of this work.

Contributors MAM and CSK conceived and planned the study. CSK and CWW performed the search for relevant studies. Data were screened, extracted and analysed by CSK and CWW. CWW wrote the first draft of the paper. All authors contributed to the interpretation of the findings and critically revised it for intellectual content.

Funding This work is supported by the ASPIRE Summer Studentship programme at Keele University.

Competing interests None declared.

Patient consent Not required.

Provenance and peer review Not commissioned; externally peer reviewed.

(c) Article author(s) (or their employer(s) unless otherwise stated in the text of the article) 2018. All rights reserved. No commercial use is permitted unless otherwise expressly granted.

\section{REFERENCES}

1 WHO. Cardiovascular diseases (CVDs). 2018. http://www.who.int/mediacentre/ factsheets/fs317/en/

2 Xie G, Zou H, Myint PK, et al. Baseline overall health-related quality of life predicts the 10-year incidence of cardiovascular events in a Chinese population. Qual Life Res 2016:25:363-71.

3 Panagiotakos DB, Pitsavos C, Kogias Y, et al. Marital status, depressive episodes, and short-term prognosis of patients with acute coronary syndrome: Greek study of acute coronary syndrome (GREECS). Neuropsychiatr Dis Treat 2008;4:425-32.

4 Hu YR, Goldman N. Mortality differentials by marital status: an international comparison. Demography 1990;27:233-50.

5 Barbash IM, Gaglia MA, Torguson R, et al. Effect of marital status on the outcome of patients undergoing elective or urgent coronary revascularization. Am Heart J 2013;166:729-36.

6 Consuegra-Sánchez L, Melgarejo-Moreno A, Jaulent-Huertas L, et al. Unraveling the relations between marital status and prognosis among myocardial infarction survivors: impact of being widowed on mortality. Int J Cardiol 2015;185:141-3.

7 Gerward S, Tydén P, Engström G, et al. Marital status and occupation in relation to short-term case fatality after a first coronary event--a population based cohort. BMC Public Health 2010;10:235.

8 Hadi Khafaji HA, Al Habib K, Asaad N, et al. Marital status and outcome of patients presenting with acute coronary syndrome: an observational report. Clin Cardiol 2012:35:741-8.

9 Vujcic I, Vlajinac H, Dubljanin E, et al. Long-term prognostic significance of living alone and other risk factors in patients with acute myocardial infarction. Ir J Med Sci 2015; 184:153-8

10 Yokoyama H, Higuma T, Nishizaki F, et al. Marital status and long-term mortality of male patients presenting with acute myocardial infarction. Circ 2014;130:S2.

11 Andersen KK, Andersen ZJ, Olsen TS. Predictors of early and late case-fatality in a nationwide Danish study of 26,818 patients with first-ever ischemic stroke. Stroke 2011:42:2806-12.

12 Samanci N, Dora B, Kizilay F, et al. Factors affecting one year mortality and functional outcome after first ever ischemic stroke in the region of Antalya, Turkey (a hospitalbased study). Acta Neurol Belg 2004;104:154-60.

13 Floud S, Balkwill A, Canoy D, et al. Marital status and ischemic heart disease incidence and mortality in women: a large prospective study. BMC Med 2014;12:24.

14 Engström G, Tydén P, Berglund G, et al. Incidence of myocardial infarction in women. A cohort study of risk factors and modifiers of effect. J Epidemiol Community Health 2000;54:104-7.

15 Kriegbaum M, Christensen U, Lund R, et al. Job loss and broken partnerships: do the number of stressful life events influence the risk of ischemic heart disease in men? Ann Epidemiol 2008; 18:743-5.

16 Kilpi F, Konttinen $\mathrm{H}$, Silventoinen K, et al. Living arrangements as determinants of myocardial infarction incidence and survival: a prospective register study of over 300,000 Finnish men and women. Soc Sci Med 2015;133:93-100.

17 Ikeda A, Iso H, Kawachi I, et al. Living arrangement and coronary heart disease: the JPHC study. Heart 2009:95:577-83.

18 Malyutina S, Bobak M, Simonova G, et al. Education, marital status, and total and cardiovascular mortality in Novosibirsk, Russia: a prospective cohort study. Ann Epidemiol 2004; 14:244-9

19 Dupre ME, George LK, Liu G, et al. Association between divorce and risks for acute myocardial infarction. Circ Cardiovasc Qual Outcomes 2015;8:244-51. 
20 Engström G, Hedblad B, Rosvall M, et al. Occupation, marital status, and low-grade inflammation: mutual confounding or independent cardiovascular risk factors? Arterioscler Thromb Vasc Biol 2006;26:643-8.

21 Moher D, Shamseer L, Clarke M, et al. Preferred reporting items for systematic review and meta-analysis protocols (PRISMA-P) 2015 statement. Syst Rev 2015;4:1.

22 Higgins JPT, Green S. Cochrane Handbook for Systematic Reviews of Interventions Version 5.1.0. London, UK: The Cochrane Collaboration, 2011.

23 loannidis JP, Trikalinos TA. The appropriateness of asymmetry tests for publication bias in meta-analyses: a large survey. CMAJ 2007;176:1091-6.

24 Janzon E, Hedblad B, Berglund G, et al. Tobacco and myocardial infarction in middleaged women: a study of factors modifying the risk. J Intern Med 2004;256:111-8.

25 Sorlie PD, Coady S, Lin C, et al. Factors associated with out-of-hospital coronary heart disease death: the national longitudinal mortality study. Ann Epidemiol 2004; 14:447-52.

26 Bell CL, LaCroix A, Masaki K, et al. Prestroke factors associated with poststroke mortality and recovery in older women in the Women's Health Initiative. J Am Geriatr Soc 2013;61:1324-30.

27 Eaker ED, Sullivan LM, Kelly-Hayes M, et al. Marital status, marital strain, and risk of coronary heart disease or total mortality: the Framingham Offspring Study. Psychosom Med 2007;69:509-13

28 Engström G, Khan FA, Zia E, et al. Marital dissolution is followed by an increased incidence of stroke. Cerebrovasc Dis 2004;18:318-24.

29 Matthews KA, Gump BB. Chronic work stress and marital dissolution increase risk of posttrial mortality in men from the Multiple Risk Factor Intervention Trial. Arch Intern Med 2002;162:309-15.

30 Dupre ME, Nelson A. Marital history and survival after a heart attack. Soc Sci Med 2016;170:114-23

31 Maselko J, Bates LM, Avendaño M, et al. The intersection of sex, marital status, and cardiovascular risk factors in shaping stroke incidence: results from the Health and Retirement Study. J Am Geriatr Soc 2009;57:2293-9.

32 Orth-Gomér K, Wamala SP, Horsten M, et al. Marital stress worsens prognosis in women with coronary heart disease: the Stockholm Female Coronary Risk Study. IAMA 2000;284:3008-14.

33 Quinones PA, Kirchberger I, Heier M, et al. Marital status shows a strong protective effect on long-term mortality among first acute myocardial infarction-survivors with diagnosed hyperlipidemia--findings from the MONICA/KORA myocardial infarction registry. BMC Public Health 2014;14:98.

34 Schultz WM, Hayek SS, Samman Tahhan A, Tahhan AS, et al. Marital status and outcomes in patients with cardiovascular disease. J Am Heart Assoc 2017;6:e005890.

35 Akimova EV, Pushkarev GS, Smaznov VY, et al. Socio-economic risk factors for cardiovascular death: data from 12-year prospective epidemiologic study. Russian Journal of Cardiology 2014;6:7-11.
36 Goldbourt U. Unmarried working men and unhappily married at age 40-65 carry excess risk of 34-year stroke mortality. American Stroke Association 2010 International Stroke Conference. 2010:P72.

37 Strand BH, Tverdal A. Can cardiovascular risk factors and lifestyle explain the educational inequalities in mortality from ischaemic heart disease and from other heart diseases? 26 year follow up of 50,000 Norwegian men and women. J Epidemiol Community Health 2004:58:705-9.

38 Ghosh-Swaby OR, Tan M, Bagai A, et al. Marital status, living arrangement, and outcomes following myocardial infarction: observations from the Canadian Observational Antiplatelet Study (COAPT). Can J Cardiol 2016;32:S220-S221.

39 Jayaram N, Buchanan D, Gosch K, et al. Understanding the protective benefits of marriage on survival after myocardial infarction. Circulation 2013;128:A12624.

40 Wolinsky FD, Bentler SE, Cook EA, et al. A 12-year prospective study of stroke risk in older Medicare beneficiaries. BMC Geriatr 2009;9:17.

41 Manzoli L, Villari P, M Pirone G, et al. Marital status and mortality in the elderly: a systematic review and meta-analysis. Soc Sci Med 2007;64:77-94.

42 Manfredini R, De Giorgi A, Tiseo R, et al. Marital status, cardiovascular diseases, and cardiovascular risk factors: a review of the evidence. J Womens Health 2017:26:624-32.

43 Fournier S, Muller O, Ludman AJ, et al. Influence of socioeconomic factors on delays, management and outcome amongst patients with acute myocardial infarction undergoing primary percutaneous coronary intervention. Swiss Med Wkly 2013;143:w13817

44 Austin D, Yan AT, Spratt JC, et al. Patient characteristics associated with selfpresentation, treatment delay and survival following primary percutaneous coronary intervention. Eur Heart J Acute Cardiovasc Care 2014;3:214-22.

45 Wu JR, Lennie TA, Chung ML, et al. Medication adherence mediates the relationship between marital status and cardiac event-free survival in patients with heart failure. Heart Lung 2012;41:107-14.

46 Kachur S, Chongthammakun V, Lavie CJ, et al. Impact of cardiac rehabilitation and exercise training programs in coronary heart disease. Prog Cardiovasc Dis 2017;60:103-14

47 Lindström M, capital S. Social capital, economic conditions, marital status and daily smoking: a population-based study. Public Health 2010;124:71-7.

48 Pennanen M, Broms U, Korhonen T, et al. Smoking, nicotine dependence and nicotine intake by socio-economic status and marital status. Addict Behav 2014;39:1145-51.

49 Kamon Y, Okamura T, Tanaka T, et al. Marital status and cardiovascular risk factors among middle-aged Japanese male workers: the High-risk and Population Strategy for Occupational Health Promotion (HIPOP-OHP) study. J Occup Health 2008:50:348-56 